\title{
Prevalence of vitamin D deficiency among adult population of Western Region of Nepal
}

\author{
Mahesh Prakash Bhatta ${ }^{1 *}$, Bhupendra Raj Pandey ${ }^{1}$, Khusi Man Gurung ${ }^{1}$, Rasmita Nakarmi ${ }^{1}$, Kshamata \\ Gurung $^{1}$, Lal Bahadur Gurung ${ }^{1}$, Srijana Rana Magar ${ }^{1}$ \\ ${ }^{1}$ United Reference Laboratory, Pokhara, Nepal
}

\begin{abstract}
Background: Vitamin D deficiency is major public health threat throughout the world, particularly among people living in low income nations like Nepal. It is a steroid hormone, vital for asserting calcium homeostasis and optimizing bone health. Decreased concentrations of vitamin D result in changes in calcium and phosphorus homeostasis, secondary hyperparathyroidism, bone loss, osteoporosis, and an increase in fracture risk. Vitamin D deficiency is determined as a level of 25-hydroxy vitamin D reduces to less than $25 \mathrm{ng}$ per milliliter. The aim of this study was to review the vitamin D condition and population-based occurrence of vitamin D deficiency, in western region of Nepal, in adult. A secondary aim was to examine determinants of vitamin D deficiency and its occurrence by gender, ethnicity and other demographic factors within this population.
\end{abstract}

Methods: A cross sectional laboratory based experimental study was done in total of 2158 subjects (19-60yrs) who visited United Reference Laboratory from $20^{\text {th }}$ July, 2014 to $17^{\text {th }}$ December, 2015. Data were collected on subjects from that days visit, including age, sex, self -declared ethnicity and place where they live. Determination of vitamin D was performed in serum of subjects in fully automated Cobas e411 analyzer. Data analysis was done by SPSS version 20.0 software.

Results: Out of 2158 subjects (692 male, 1466 female), 1590 (73.68\%) had vitamin D deficiency, whereas only 568 (26.32\%) had optimum level of vitamin D. Females were more deficient than male by $5.29 \%(P=0.016)$. Deficiency of vitamin D was found significant in all season, but deficiency percentage increases during winter $(81.62 \%)$ and spring $(88.82 \%)$ as compared to autumn $(57.07 \%)$ and summer $(70.39 \%)(P=0.00)$. It was found that Brahmins were significantly more deficient of vitamin $\mathrm{D}$ as compared to other ethnic group $(P=0.00)$.

Conclusion: There is high prevalence of vitamin D deficiency in $73.68 \%$ of working adult population of Western Region of Nepal. This finding evinces that vitamin D deficiency is significantly associated with gender, season, and ethnicity variable.

Keywords: Cobas e411, Ethnicity, Gender, Season, 25-hydroxy vitamin D [25(OH)D]

\section{BACKGROUND}

Vitamin D denotes cholecalciferol, produced by the action of ultraviolet light with a wavelength of 290-320 $\mathrm{nm}$ on 7- dehydrocholesterol in the skin of humans. Once made in the skin or ingested, vitamin D is transported to the liver from kidney where it is hydroxylated into 25hydroxy vitamin, which is the major circulating form of vitamin D [1].
Vitamin D is a steroid hormone with pleiotropic effects on calcium and phosphorus metabolism and the immune system[2].

* Correspondence: Mahesh Prakash Bhatta

${ }^{1}$ United Reference Laboratory, Pokhara, Nepal

E-mail: bhattamahesho4@gmail.com

Tel: 00977 - 9804112854 
Vitamin $\mathrm{D}$ is essential for maintaining calcium homeostasis and bone health. Low concentrations of vitamin D lead to alterations in calcium and phosphorous homeostasis, secondary hyperparathyroidism, bone loss, osteoporosis, and an increase in fracture risk [3]. The standard method of assessing vitamin D status is by measuring serum concentration of the major circulating metabolite of vitamin D, 25-hydroxy vitamin D [25(OH)D] [3].

Low levels of 25-hydroxy vitamin D [25(OH)D], the principal circulating storage form of vitamin $\mathrm{D}$, are present in as many as one third to one half of otherwise healthy middle-aged to elderly adults [4]. The high prevalence of low vitamin D status is assumed to result from inadequate sun exposure [5]. Increasing urbanization that results in poor outdoor activity and greater pollution, coupled with skin pigment, may further compound this problem [6]. Although there is no consensus on optimal levels of 25hydroxy vitamin D as measured in serum, vitamin D deficiency is defined by most experts as a 25-hydroxy vitamin D level of less than 20 ng per millilitre [7].

Over the past two decades, several national populationbased epidemiological studies in the United States, Canada, United Kingdom, and New Zealand have reported that $52-77 \%$ of the populations had $25(\mathrm{OH}) \mathrm{D}$ levels $<75 \mathrm{nmol} / \mathrm{l}$ and $18 \%$ to $36 \%$ had levels $<50 \mathrm{nmol} / \mathrm{l}$ [8]. In Australia, vitamin D deficiency has been identified as a problem in certain subgroups, including elderly people, dark skinned and veiled women and those living in residential care [8].

The aim of this study was to assess the vitamin D status and population-based prevalence of vitamin D deficiency in western region of Nepal. This is the first epidemiological study to have evaluated the vitamin D status in western region of Nepal. A secondary aim was to examine determinants of vitamin D deficiency and compare the prevalence rates by gender, ethnic, and other demographic factors within this population.

\section{METHODOLOGY}

\section{Study population}

We studied 2158 patients (19-60 years) who visited United Reference Laboratory from $20^{\text {th }}$ July, 2014 to $17^{\text {th }}$ December, 2015. Exclusion criteria included a chronic illness and use of medications known to affect bone metabolism. All participants provided oral informed consent. The Committee on Clinical Investigation, URL approved the protocol.

\section{Data collection}

Data were collected on patients from that day's visit, including age, sex, self-declared ethnicity and place where they live.

\section{Laboratory measurements}

One blood sample $(5 \mathrm{~mL})$ was obtained in gel tube for each subject and serum was separated by the use of centrifuge to estimate vitamin D [25(OH)D]. Vitamin D estimation was performed in the United Reference Laboratory (URL) using kits provided by the Roche. Serum 25(OH)D levels were measured by automated electrochemiluminescence (ECLIA, Cobas e411, Roche diagnostics, Germany). On the basis of serum 25(OH)D concentrations, patients were divided into 3 diagnostic categories, as rounded to the nearest integer. Subjects with $25(\mathrm{OH}) \mathrm{D}$ level concentration less than $10 \mathrm{ng} / \mathrm{ml}$ were classified as severe deficiency, 10 to $24 \mathrm{ng} / \mathrm{ml}$ as mildmoderate deficiency and greater than or equal to $25 \mathrm{ng} / \mathrm{ml}$ as optimum level [9].

\section{Statistical analysis}

Data analysis was done by using Statistical Package for the Social Sciences (SPSS) Version 20.0. Mean value and standard deviation were represented as mean \pm S.D. Data with $\mathrm{P}$ value $\leq 0.05$ were considered to be significant. 


\section{RESULTS}

The present article is based on laboratory based cross sectional study of 2158 samples of adult (19-60 years). Population aged less than 19 years and greater than 60 years were not included in this study, only working population were included. This report is focused on the distribution and determination of vitamin D status in the adult population of western region of Nepal.

\section{Status of vitamin D on the basis of level and gender}

Out of total 2158 samples collected from participants visiting united reference laboratory, 394 subjects (18.26\%) were under severe deficiency whereas nearly greater than half, (55.42\%) 1196 accounted for mild to moderate deficiency, and only remaining (26.32\%) 568 have optimum levels of vitamin D as shown in Fig $\mathbf{1}$.

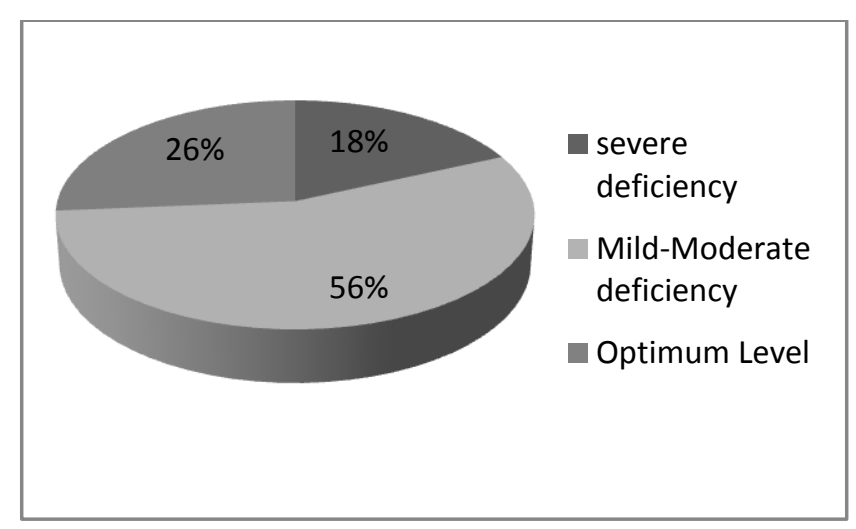

Fig 1: Vitamin D status of adult population

In the context of male and female, out of 692 male, 119 $(17.20 \%)$ were in severe deficient phases, 366 (52.89\%) were in mild to moderate deficient phases and remaining 207 (29.91\%) had optimum levels of vitamin D. Similarly out of 1466 female, 275 (18.76\%) were severely deficient, $830(56.62 \%)$ were mild to moderately deficient and remaining 361 (24.62\%) had optimum levels of vitamin D. Comparatively, in the overall perspective, female showed more Vitamin D deficiency than male as shown in Fig 2 and Table 1.

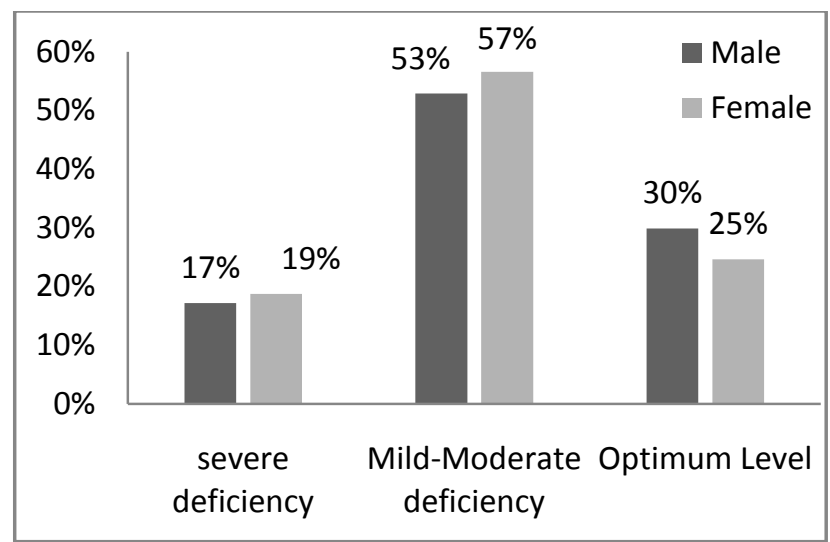

Fig 2: Status of Vitamin D among Male and Female

Table 1: Mean value and standard deviation of Vitamin D

\begin{tabular}{l|cccccc|} 
& \multicolumn{2}{c}{ Total } & \multicolumn{2}{c}{ Male } & \multicolumn{2}{c}{ Female } \\
\cline { 2 - 7 } $\begin{array}{l}\text { 25(OH)D } \\
\text { Trends }\end{array}$ & Mean & S.D. & Mean & S.D. & Mean & S.D. \\
$\begin{array}{l}\text { Severe } \\
\text { deficient }\end{array}$ & 6.49 & 2.49 & 6.83 & 2.02 & 6.35 & 2.21 \\
$\begin{array}{l}\text { Mild- } \\
\text { Moderate } \\
\text { deficient }\end{array}$ & 17.20 & 4.16 & 17.29 & 3.97 & 17.16 & 4.24 \\
$\begin{array}{l}\text { Optimum } \\
\text { levels }\end{array}$ & 33.19 & 8.08 & 33.06 & 7.99 & 33.6 & 8.14 \\
\hline
\end{tabular}

S.D. $=$ Standard Deviation

\section{Status of vitamin D on the basis of season}

Seasonal wise study reveals, $10.30 \%$ of population were severely deficient, $60.08 \%$ of population were in mild to moderate deficient phase and $29.62 \%$ of population had optimum level of vitamin D in summer. Similarly $5.40 \%$ of population were severely deficient, $51.65 \%$ of population were in mild to moderate deficient phase and $42.93 \%$ of people had optimum level in autumn, whereas in winter $28.88 \%$ of population were severely deficient, $53.33 \%$ of population were in mild to moderate deficient phase and $17.79 \%$ had optimum levels. Likewise, $34.18 \%$ 
of population were severely deficient, $54.63 \%$ of population were in mild to moderately deficient phase and $11.18 \%$ had optimum level of vitamin D in spring (Fig 3).

This study utterly indicates most of people were vitamin D deficient especially during winter (16.19+9.71) and spring (14.68+9.41) as compared to summer $(20.93 \pm 9.61)$ and autumn (24.4 \pm 10.93$)$. Vitamin D is found at optimum level mainly in autumn and in summer. This study elucidates, people are more deficient of vitamin D in spring and then in winter as a whole.

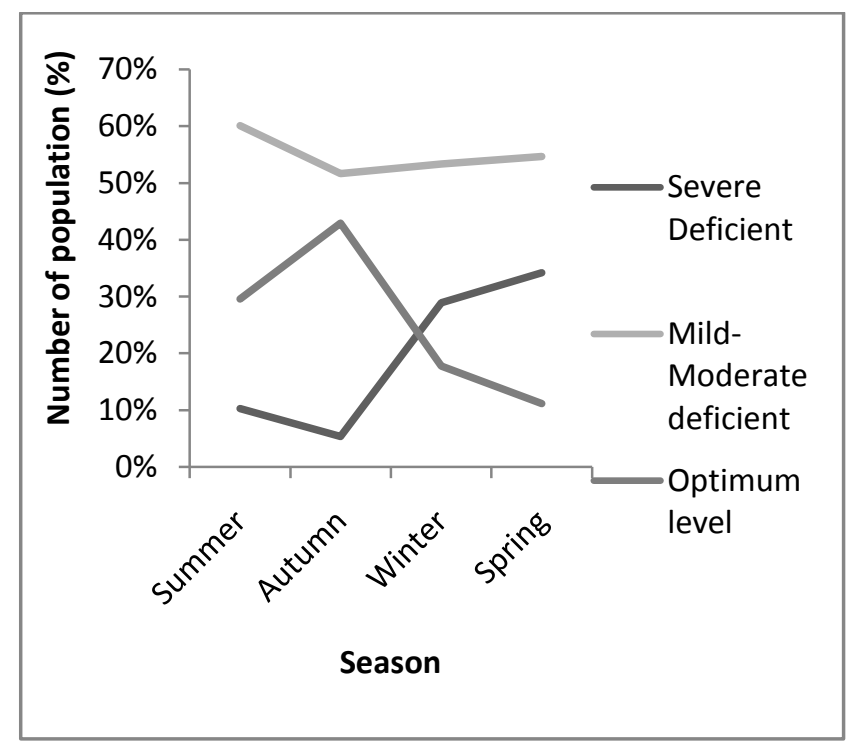

Fig. 3: Seasonal wise Vitamin D patterns

\section{Status of vitamin D on the basis of ethnicity}

The study shows, all ethnic group population were vitamin D deficient, out of which, Brahmins were most deficient, followed by Chhetri, Dalit, Newar, Gurung and other ethnic groups whereas Magar community was least deficient of vitamin D. This study shows, in all ethnic groups vitamin D is significantly deficient, and amongst them, most in Brahmin and least in Magar (Fig 4).

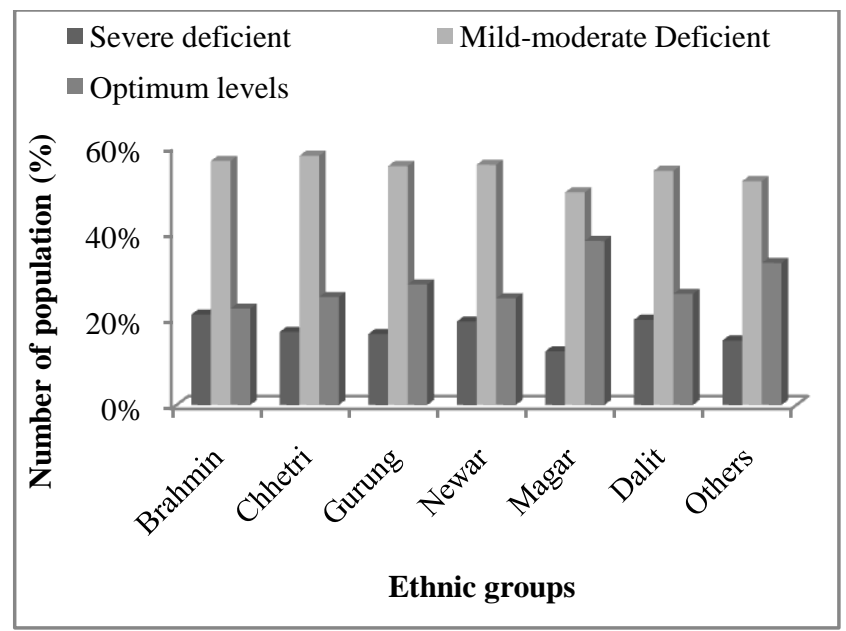

Fig 4: Distribution of vitamin D among ethnic group

\section{DISCUSSION}

This was cross-sectional laboratory based experimental study, conducted mainly to determine prevalence of vitamin $\mathrm{D}$ deficiency and compare prevalence rate with gender, season and ethnicity in western region of Nepal. According to this study, the prevalence rate of vitamin D deficiency was $73.68 \%$ (1590 out of 2158 subjects) in adult population. This study showed significant deficiency of vitamin $\mathrm{D}$ in adult population of Western Region of Nepal. Similar data was presented in the study conducted by Gannagé-Yared et al., showing $72.8 \%$ of population affected by hypovitaminosis D [10].

This study elucidated females were significantly more deficient of vitamin D as compared to male (70.08\% vs. $75.37 \%)(P=0.016)$. This is due to socio economic status as most of male were exposed to external environment that is working outside at sun for long time. Study by Roomi et al. in India also found similar outcome, that is female are significantly more deficient than male [11], which is also supported by Verdoia et al [12], Gannagé-Yared et al [10], and also by Bolland et al. [13].

Deficiency of vitamin D was found significant in all season, but more deficient during winter (81.62\%) and spring $(88.82 \%)$ as compared to autumn (57.07\%) and 
summer $(70.39 \%)(P=0.00)$, which was similar to the findings of van der Mei et al , Goswami et al and Daly et al $[14,8,15]$. Study done in Australian population by Gill et al [16] and Korean adults by Choi [17] also demonstrated the similar outcome.

In context of ethnicity wise comparison of prevalence rate of vitamin D deficiency, there were still no any data available related to it, but in our study, vitamin D was found significantly more deficient in Brahmin (77.7\%) and least in Magar $(61.9 \%)(P=0.00)$.

\section{CONCLUSION}

Our study shows significant deficiency of vitamin D among working population of Western Region of Nepal. The prevalence of insufficiency is significantly more in female population than in male population. It is also observed that vitamin D is significantly less deficient in summer and autumn as compared to winter and spring. It is less deficient in Magar as compared to other ethnic groups. This finding evinces, vitamin D variation is significantly associated with gender, season, and ethnicity variable.

\section{COMPETING INTERESTS}

The authors declare that they have no competing interests concerning the work reported in this paper.

\section{CONTRIBUTIONS}

MPB, KG, LBG, RN, SRM performed the sample collection, data collection and laboratory experiments. BRP supervised and guided in the research. MPB, KMG performed statistical analysis, conceived part of this study and revised the manuscript. All authors read and approved the final manuscript.

\section{ETHICAL CONSIDERATION}

This study was approved by Institutional Review Committee of United Reference Laboratory, Pokhara,
Nepal. Informed verbal agreement was taken from patients.

\section{ACKNOWLEDGEMENTS}

The study was funded by the United Reference Laboratory (URL), Pokhara, Nepal. We would like to thank Mr. Thakur Prasad Panta, managing director, Mr. Sushil Thapa, advisor, Board of directors as well as the entire team of URL for their unlimited support without which this work would not have been completed.

\section{REFERENCES}

1. Munns C, Zacharin MR, Rodda CP, Batch JA. Prevention and treatment of infant and childhood vitamin D deficiency in Australia and New Zealand: a consensus statement. Medical Journal of Australia. 2006;185(5):268.

2. Hintzpeter B, Scheidt-Nave C, Müller MJ, Schenk L, Mensink GB. Higher prevalence of vitamin D deficiency is associated with immigrant background among children and adolescents in Germany. The Journal of nutrition. 2008;138(8):1482-90.

3. Holick MF, Siris ES, Binkley N, Beard MK, Khan A, Katzer JT, et al. Prevalence of vitamin D inadequacy among postmenopausal North American women receiving osteoporosis therapy. The Journal of Clinical Endocrinology \& Metabolism. 2005;90(6):3215-24.

4. Gordon CM, DePeter KC, Feldman HA, Grace E, Emans SJ. Prevalence of vitamin D deficiency among healthy adolescents. Archives of pediatrics \& adolescent medicine 2004;158(6):531-7.

5. Binkley N, Novotny R, Krueger D, Kawahara T, Daida YG, Lensmeyer G, et al. Low Vitamin D Status despite Abundant Sun Exposure. The Journal of Clinical Endocrinology \& Metabolism. 2007;92(6):2130-5. 
6. Sachan A, Gupta R, Das V, Agarwal A, Awasthi PK, Bhatia V. High prevalence of vitamin D deficiency among pregnant women and their newborns in northern India. The American journal of clinical nutrition. 2005;81(5):1060-4.

7. Holick MF. Vitamin D deficiency. New England Journal of Medicine. 2007;357(3):266-81.

8. Daly RM, Gagnon C, Lu ZX, Magliano DJ, Dunstan DW, Sikaris KA, et al. Prevalence of vitamin D deficiency and its determinants in Australian adults aged 25 years and older: a national, population-based study. Clinical endocrinology. 2012;77(1):26-35.

9. Pardanani A, Drake MT, Finke C, Lasho TL, Rozell SA, Jimma $\mathrm{T}$, et al. Vitamin $\mathrm{D}$ insufficiency in myeloproliferative neoplasms and myelodysplastic syndromes: clinical correlates and prognostic studies. American journal of hematology. 2011;86(12):1013-6.

10. Gannagé-Yared MH, Chemali R, Yaacoub N, Halaby G. Hypovitaminosis D in a sunny country: relation to lifestyle and bone markers. Journal of bone and mineral research. 2000;15(9):1856-62.

11. Roomi MA, Farooq A, Ullah E, Lone KP. Hypovitaminosis $\mathrm{D}$ and its association with lifestyle factors. Pakistan journal of medical sciences. 2015;31(5):1236-40.

12. Verdoia M, Schaffer A, Barbieri L, Di Giovine G, Marino P, Suryapranata $\mathrm{H}$, et al. Impact of gender difference on vitamin D status and its relationship with the extent of coronary artery disease. Nutrition, metabolism, and cardiovascular diseases : NMCD. 2015;25(5):464-70.

13. Bolland MJ, Grey AB, Ames RW, Horne AM, Mason BH, Wattie DJ, et al. Age-, gender-, and weight-related effects on levels of 25-hydroxyvitamin D are not mediated by vitamin $\mathrm{D}$ binding protein. Clinical endocrinology. 2007;67(2):259-64.
14. van der Mei IA, Ponsonby A-L, Engelsen O, Pasco JA, McGrath JJ, Eyles DW, et al. The high prevalence of vitamin D insufficiency across Australian populations is only partly explained by season and latitude. Environmental health perspectives. 2007:1132-9.

15. Goswami R, Gupta N, Goswami D, Marwaha RK, Tandon N, Kochupillai N. Prevalence and significance of low 25hydroxyvitamin D concentrations in healthy subjects in Delhi. The American journal of clinical nutrition. 2000;72(2):472-5.

16. Gill TK, Hill CL, Shanahan EM, Taylor AW, Appleton SL, Grant JF, et al. Vitamin D levels in an Australian population. BMC public health. 2014;14(1):1.

17. Choi EY. 25(OH)D status and demographic and lifestyle determinants of $25(\mathrm{OH}) \mathrm{D}$ among Korean adults. Asia Pacific journal of clinical nutrition. 2012;21(4):526-35.

\section{Article History:}

Received: 25 December, 2015

Accepted: 25 January, 2016

Published online: 15 February, 2016

\section{For Citation:}

Bhatta MP et al.: Prevalence of vitamin D deficiency among adult population of Western Region of Nepal. International Journal of Medicine \& Biomedical Sciences. 2016: 1(2):7-12 